Artigos Originais

\title{
Ocupações artísticas no Centro Histórico de São Luís, MA: revitalização, democratização e valorização do patrimônio cultural ludovicense
}

\author{
Artistic occupations in the Historic Center of São Luís, MA: revitalization, democratization and enhancement of \\ ludovician cultural heritage \\ Ocupaciones artísticas en el Centro Histórico de São Luís, MA: revitalización, democratización y valorización del \\ patrimonio cultural ludovícico
}

Donny Wallesson dos Santos

Universidade Federal do Maranhão (UFMA), Brasil

dws87@outlook.com

Maurício José Morais Costa
Centro Universitário Unidade de Ensino Superior Dom
Bosco(UNDB),Brasil
mauriciojosemorais@gmail.com

Conceição de Maria Belfort de Carvalho

Universidade Federal do Maranhão (UFMA), Brasil

cbelfort@globo.com
DOI: https://doi.org/10.18472/cvt.21n3.2021.1919 Redalyc: https://www.redalyc.org/articulo.oa? id $=115469516011$

Recepción: 13 Marzo 2021

Aprobación: 11 Septiembre 2021

\section{Resumo:}

Estudo de campo, exploratório e descritivo, que utiliza a pesquisa bibliográfica e entrevistas semiestruturadas, com o objetivo de discutir como as ocupações "A Vida é uma Festa" e "O Circo Tá na Rua”, do Centro Histórico de São Luís, contribuem para a revitalização, democratização, preservação e valorização do patrimônio da cidade. Conceitua patrimônio cultural e caracteriza as ocupações artísticas de São Luís. Pontua que as ocupações artísticas ressignificam os espaços e possibilitam a permanência dinâmica da ideia de que patrimônio cultural não se limita a ruínas, casarões, obras e monumentos intocáveis, mas de um patrimônio vivo e em reconstrução pelas relações políticas, sociais e culturais entre aqueles que o habitam. Acentua a relação que há entre as ocupações e o patrimônio, aproximando-se da perspectiva dinâmica que preconiza seu contínuo desenvolvimento, com modificações advindas dos usos contemporâneos que lhe são dados, colocando os sujeitos como parte dele. Finaliza acentuando que as ocupações artísticas reivindicam a preservação e valorização patrimonial por meio do seu uso, mediante a aproximação das pessoas com os bens culturais que compõem a história do local e da nação.

Palavras-Chave: Ocupações Artísticas, Centro Histórico de São Luís, Patrimônio Cultural, Revitalização do Espaço Público.

\section{ABstract:}

Exploratory and descriptive field study, using bibliographic research and semi-structured interviews, with the aim of discussing how the occupations "Life is a Party" and "The Circus is on the Street", of the Historic Center of São Luís, contribute to the revitalization, democratization, preservation and enhancement of the city's heritage. Conceptualizes cultural heritage and characterizes the artistic occupations of São Luís. It points out that artistic occupations give new meaning to spaces and enable the dynamic permanence of the idea that cultural heritage is not limited to ruins, mansions, works and monuments untouchable, but a living heritage that is being reconstructed through political, social and cultural relations between those who inhabit it. It emphasizes the relationship between occupations and heritage, approaching the dynamic perspective that advocates its continuous development, with changes arising from the contemporary uses that are given to it, placing the subjects as part of it. It ends by emphasizing that artistic occupations claim the preservation and enhancement of heritage through their use, through bringing people closer to the cultural assets that make up the history of the place and the nation.

KEYWORDS: Artistic Occupations, Historic Center of São Luís, Cultural heritage, Revitalization of Public Space.

\section{ReSUMEN:}


Estudio de campo exploratorio y descriptivo, que utiliza investigación bibliográfica y entrevistas semiestructuradas, con el objetivo de discutir cómo las ocupaciones "La vida es una fiesta" y "El circo está en la calle", del Centro Histórico de São Luís, contribuyen a la revitalización, democratización, preservación y valorización del patrimonio de la ciudad. Conceptualiza el patrimonio cultural y caracteriza las ocupaciones artísticas de São Luís. Señala que las ocupaciones artísticas dan un nuevo significado a los espacios y posibilitan la permanencia dinámica de la idea de que el patrimonio cultural no se limita a ruinas, casonas, obras y monumentos intocables, sino a un patrimonio vivo que se reconstruye a través de las relaciones políticas, sociales y culturales entre quienes lo habitan. Enfatiza la relación entre ocupaciones y patrimonio, acercándose a la perspectiva dinámica que aboga por su continuo desarrollo, con cambios derivados de los usos contemporáneos que se le dan, colocando a los sujetos como parte de él. Finaliza enfatizando que las ocupaciones artísticas reclaman la preservación y puesta en valor del patrimonio a través de su uso, mediante el acercamiento de las personas a los bienes culturales que componen la historia del lugar y de la nación.

Palabras Clave: Ocupaciones artísticas, Centro Histórico de São Luís, Patrimonio cultural, Revitalización del espacio público.

\section{INTRODUÇÃo}

O Centro Histórico de São Luís (CHSL) é conhecido nacionalmente por reunir um dos maiores conjuntos arquitetônicos civis com traços de origem europeia e se destaca como um dos principais cartóes postais da cidade (Chaves, 2012). Apesar de ser parte da história da capital, é visível o abandono do lugar. Algumas iniciativas foram tomadas pelo poder público no sentido de revitalizar esse espaço: uma delas foi o desenvolvimento de uma política de ocupação por coletivos artísticos.

Sendo um dos principais expoentes, tanto do Estado do Maranhão, quanto do Brasil em termos de patrimônio (Chaves, 2012; Costa, 2017), o CHSL tem sido objeto de estudo nos mais distintos campos do conhecimento. Investigar suas nuances é fundamental não apenas para tornar evidentes os bens ali localizados, como também para tornar conhecidas ações que favorecem a preservação e a valorização desse espaço que, com o passar do tempo, ganha relevância não apenas por seu patrimônio arquitetônico, como também por sua riqueza cultural. Diante disso, o presente estudo tem como objetivo geral discutir as implicações das ocupações artísticas presentes no CHSL e destacar como estas podem contribuir, não apenas para sua revitalização como, também, para a democratização, preservação e valorização do patrimônio cultural da capital maranhense, a partir do uso de seus espaços públicos.

Nessa perspectiva, trata-se de um estudo de natureza exploratória e descritiva (Sampieri, Collado, \& Lucio, 2013), que utiliza como instrumentos a pesquisa bibliográfica (Marconi \& Lakatos, 2017) como mecanismo para dialogar como autores que tratam de Patrimônio Cultural e Ocupações Artísticas, dentre eles: Choay (2009), Garcia (2017), Paiva e Gabbay (2016), Medeiros (2002), Fonseca (2009), entre outros. De abordagem qualitativa (Marconi \& Lakatos, 2017), procedeu-se a análise das produções, buscando conjugar as categorias tratadas pelos autores ao objeto de investigação, notadamente, as ocupações no Centro Histórico de São Luís, Maranhão. Para tal, foram investigados os coletivos “A Vida é uma Festa” e "O Circo Tá na Rua” instaladas no Centro Histórico de São Luís, com vistas a analisar como estes contribuem para a revitalização, democratização, preservação e valorização do patrimônio cultural da cidade, a partir de dados empíricos provenientes de entrevistas semiestruturadas, cujos depoimentos foram coletados entre outubro e novembro de 2019, mediante pesquisa de campo com apoio do diário de bordo (Sampieri, Collado, \& Lucio, 2013).

O artigo está organizado em três seções principais. Na primeira seção abordam-se as ocupações artísticas, sobretudo em como estas se constituem. Na segunda seção discorre-se acerca do patrimônio cultural em sua perspectiva teórico-conceitual, bem como fala sobre o tombo patrimonial. Na terceira seção discutemse as implicações das ocupações artísticas no Centro Histórico de São Luís, e, como tais contribuem para a preservação e valorização do patrimônio cultural do Maranhão. Caracteriza o Centro Antigo de São Luís, além de refletir sobre o papel das ocupações artísticas e suas implicações para o patrimônio cultural de São Luís. 


\section{OCuPaÇões artísticas E ESPAÇO PÚblico: BREVES CONSIDERAÇÕES}

Em meados do século XX destaca-se um considerável interesse em analisar os processos sociais característicos de determinados espaços urbanos. Ganham visibilidade importante estudos como os de Walter Benjamin, Georg Simmel, Max Weber e Guy Debord, este último pioneiro nas problematizações acerca da vida cotidiana, no intuito de quebrar sua lógica alienada pelo capital (Conceição, 2011). Conceição (2011) observa que há uma complexidade peculiar na relação das pessoas com a cidade e com os espaços que nela se estabelecem, a qual resulta diretamente da fruição de transformações históricas, políticas, econômicas, sociais e individuais. Paiva e Gabbay (2016, p. 4) ampliam o olhar ao colocar "[...] a cidade como espaço psíquico, graças à produção de uma cadeia de afetos coletivamente sustentados [...]" no espaço público, visto como local de democracia, se estabelecem relações entre os indivíduos de produção comum: espaços para trocas, contatos, diálogos e afetos.

Nessa perspectiva do espaço público como lugar de democracia, Sartori e Garcia (2013) ratificam a rica complexidade de exploração das relações pertencentes a ele, caracterizando-o como um espaço de formação e discussão da agenda pública, negociada pela participação efetiva da sociedade civil na sua elaboração. Mas também salientam a prevalência dos interesses privados sobre os interesses públicos na utilização dos espaços da cidade, ou seja, as elites (burguesia e Estado) detêm o poder de utilização dos espaços em detrimento das necessidades e dos direitos da população em usufruí-los.

Corroborando com essa ideia, Paiva e Gabbay (2016) localizam uma relação de causalidade entre a ocupação dos espaços públicos e a privatização das cidades. Países em desenvolvimento, como o Brasil, adotam um modelo de urbanização norte americanizado que se impõe à população: uma cidade global repleta de centros comerciais, shoppings, grandes prédios, num estado de contínua vigilância e assepsia.

Adentrando na percepção artística de utilização dos espaços públicos, as práticas do fazer artístico na rua inevitavelmente criam laços entre o corpo do indivíduo e o corpo urbano, criando ligações visíveis e invisíveis entre todos que participam da ação. Essa forma de apropriar-se do espaço, criando vínculos sociais, vai de encontro às relações espaciais provenientes da metropolização, nas quais desaparece o estar e compartilhar com o outro e as transformações radicais em tradições praticadas pela comunidade local (Moreaux, 2013).

Tais coletivos que emergem nas cidades identificam e legitimam seus reais problemas e propóem formas de solucioná-los, algo que outrora era comum em pequenas cidades hoje se torna necessário nas grandes metrópoles, em uma real necessidade de reorganizar a cidade e seus espaços públicos (Durán, 2008). Assim, Garcia (2017) salienta sobre novas configurações socioespaciais de cultura e cidade, que tais ressignificações do espaço público ocorrem porque há uma identidade coletiva, galgada em valores simbólicos de ampliação das características comuns aos residentes e utilizadores daquele espaço, mediante a construção de signos de bem-estar e satisfação.

Pode-se considerar as ocupações artístico-culturais como um modelo de ação coletiva que se utiliza de práticas artísticas em espaços urbanos vazios, abandonados ou subutilizados, como ferramenta política de reflexão e mobilização da sociedade, a fim de promover plena participação na sua gestão e utilização, colocando-se como movimento social de reivindicação e resistência à mercantilização do espaço público pelo sistema capitalista, promovendo a prática da democracia direta, da cidadania e do direito à cidade.

\section{Patrimônio cultural: conceitos e Sentidos}

Pensar o Patrimônio Cultural e o que ele representa leva-nos à necessidade de rememorar - mesmo que de forma breve - sua constituição e conceituação. Embora passadas inúmeras décadas, sua construção semântica ainda é marcada por novas categorizações e apropriações. De antemão, dá-se início, buscando no léxico da palavra uma primeira tentativa de estabelecer um conceito. Vogt (2008) acentua que Patrimônio tem origem no latim patrimonium, que significa herança paterna, ou aquilo que integra o pater, ou seja, ao pai. 
Silva (2017) complementa, acentuando que, no âmbito da língua portuguesa, o termo "patrimônio" é definido como aquilo herdado dos pais, bens familiares. Nesse sentido, Choay (2009) destaca que a concepção de patrimônio se relaciona com as estruturas familiares, porém, com o passar do tempo também contemplou outras significações, agregando aspectos genético, histórico e cultural. Relacionando-se como diferentes aspectos, não apenas na perspectiva patriarcal, mas muito associado a monumento, isso em detrimento da influência da Arquitetura, Artes Visuais, Antropologia e História (Pereira, 2017), acentua-se que a gênese do que se entende por patrimônio se deu a partir do século XVIII, sendo que na Antiguidade Clássica e na Idade Medieval o termo também teve grande notoriedade (Choay, 2009).

Os entendimentos apontados por Pereira (2017) e Choay (2009), reverberam na visão que a sociedade tem do patrimônio cultural, ao passo em que estes são enxergados como algo intocável, de acesso restrito, que desvela a resistência que a população tem diante das próprias ocupações no Centro Histórico de São Luís, por exemplo, visto por vezes como algo transgressor. Outrossim, ressalta-se que a concepção de monumento deu condições reflexivas para que o próprio conceito de patrimônio fosse delineado, visto a histórica importância dada à demarcação, controle e enumeração de monumentos, como bem pontua Studart (2017).

De acordo com Rocha (2018), a construção histórica do significado de patrimônio ampliou-se e modificou-se, deixando de contemplar apenas os monumentos históricos, mas dando destaque para elementos como a língua, ritmos, gostos e sabores. Sendo assim, destaca-se que "O patrimônio cultural é um processo de construção simbólica que possui dimensóes como a sociocultural, a natural, a técnica, a política e a econômica" (Fernandes, 2017, p. 32).

Dessa forma, pode-se afirmar que a chegada do século XX trouxe consigo a ampliação do domínio patrimonial, tendo em vista que tudo que diz respeito ao patrimônio, sobretudo seus objetos, necessitavam encontrar "ressonância" na sociedade, cujas ações de conceituação e aplicação se delineavam. Após a Segunda Guerra Mundial, os propósitos e valores do patrimônio foram requalificados, mormente nas sociedades ocidentais contemporâneas, como explicam Choay (2009) e Grimaldi (2016).

Partindo disso, ressalta-se que "O patrimônio, atualmente, é usufruto de uma vasta gama de atividades. No âmbito cultural, foi incorporado devido a sua produtividade artística e artesanal, além da visão que considera artefatos e bens intangíveis como dignos de preservação" (Silva, 2017, p. 16). No arranjo de elementos que intentam delinear o patrimônio cultural apresentados por Silva (2017), é possível incluir as ocupações artísticas, visto estas serem, também, responsáveis por notável produção artística e pela sua presença na ressignificação de espaços públicos, tal como as que são alvo deste estudo. Conforme explicitado, afirma-se que os bens patrimoniais ora elencados, são expoentes importantes para a consolidação do entendimento de patrimônio e o que ele representa, não se restringindo apenas as construções arquitetônicas.

Nessa assertiva, Rocha (2018, p. 28) afirma que o Patrimônio pode ser compreendido como “[...] os bens históricos e culturais, de caráter coletivo, ou seja, pertencente a um determinado grupo social com a pretensão de expressar um dado momento ou memória coletiva, servindo para construir e/ou reforçar a memória identitária desse grupo." Outrossim, é pertinente acentuar que no limiar do século XX o patrimônio histórico e artístico nacional passou a englobar a natureza, que segundo Medeiros (2002, p. 41), é "[...] compreendida, então, como 'paisagem', e aos objetos e sítios de caráter arqueológicos [...]." Desse modo, vivia-se um novo momento para o patrimônio, uma vez que suas dimensões transcendiam os limites nacionais, conquistando espaços internacionais, abrindo caminho para a UNESCO (Pereira, 2017; Medeiros, 2002).

A preservação do patrimônio emerge na necessidade de espaços capazes de preservar e salvaguardar a memória. Memória, também é colocada como uma importante categoria relacionada ao patrimônio. Nesse sentido, destaca-se a patrimonialização como mecanismo político-institucional que reforça a importância do patrimônio como ente responsável pela memória pública de um povo. Desse modo, conforme Funari e Pelegrini (2009), patrimonializar consiste em legitimar um bem público que, por sua vez, deve ser preservado.

Portanto, o patrimônio cultural - tanto material, quanto imaterial - é dotado de várias dimensões, que devem ser não apenas preservadas, mas por representarem todo um legado histórico de nossos antepassados, 
devem ser transmitidos às futuras gerações. Com isso, o patrimônio irá adquirir novos significados e interpretações, ou seja, irá compor novas realidades. Sendo assim, o mesmo deve ser compreendido como uma formação discursiva, responsável por mapear conteúdos simbólicos, não restringindo-se à simples descrição de como uma determinada nação é formada mas, sobretudo, como esta constrói sua identidade cultural.

O Centro Histórico de São Luís compõe o patrimônio da cidade e nos últimos anos tem sido espaço de atividades diversificadas, dentre elas a Feira de Livros, festivais de música alternativa e popular brasileira, intervenções e ocupações artísticas. Tais práticas não apenas ressignificam, como dão uma nova perspectiva para esse espaço carregado de memória e símbolos da cultura maranhense. Na seção seguinte, discute-se como tais práticas, sobretudo as ocupações artísticas, incidem em ações de cidadania, preservação e valorização do patrimônio público do Estado.

É pertinente acentuar que identificar, preservar e conservar os bens materiais e imateriais por si só não é suficiente; para que, de fato, as ações sejam consolidadas, é indispensável o trabalho interdisciplinar junto à população, a partir dos espaços de socialização do patrimônio cultural, colocando em evidência as ocupações artísticas, sobretudo as que atuam como vetores de requalificação e ressignificação dos espaços públicos de São Luís, instaladas no Centro Histórico da capital. Nesse sentido, prossegue-se na próxima seção abordando como tais ocupações podem ser notáveis vetores de fomento ao desenvolvimento de políticas e ações de preservação do patrimônio cultural, bem como vetores de incentivo ao turismo, uso consciente dos espaços públicos, fortalecimento e exercício da cidadania.

\section{As OcupaÇões Artísticas e suas implicaÇões para a ValorizaÇão do patrimônio CULTURAL DE SÃo LUÍs-MA}

Ao longo desta seção, faz-se uma breve reconstrução e caracterização histórico-temporal do CHSL, na perspectiva de compreender como se constitui esse importante espaço cultural e berço da sociedade ludovicense. Além disso, discute-se como as atividades e ocupações artísticas desse espaço público e tombado podem contribuir com a formação cidadã, bem como as noções de preservação e valorização do patrimônio cultural maranhense.

\subsection{Centro Histórico de São Luís: a Praia Grande}

O Centro Histórico de São Luís é conhecido internacionalmente por sua beleza e por se tratar de área de grande valor histórico e cultural, além de arquitetônico e paisagístico (Cutrim; Costa; Oliveira, 2017). A região central da capital maranhense teve seu surgimento associado aos principais locus econômico, o porto e sua região litorânea. A região da Praia Grande foi o grande núcleo comercial dos primórdios da colonização de São Luís, tornando-se o ponto de carga e descarga do fluxo mercadológico de importação e exportação, constituindo-se, a gênese da cidade e da sociedade ludovicense[1].

Sendo o centro de São Luís fruto de ações humanas, sobrepostas por diferentes períodos do tempo, e considerando o avanço do comércio e das relações comerciais estabelecidas na Praia Grande, seu valor histórico e cultural consolidou-se, e hoje ele é considerado um dos mais importantes espaços da capital do Maranhão (Noronha, 2015). O Centro Histórico de São Luís possui características únicas. É um local onde a cultura e a história maranhense expressam-se por meio de elementos tangíveis e intangíveis, em aromas e sabores, manifestações culturais e ocupações, responsáveis por manterem vivas e resgatarem toda a memória e identidade do local (Cutrim, Costa \& Oliveira, 2017, Santos \& Lorêdo, 2013, Ferreira, 2008).

O Centro Histórico de São Luís tem uma extensão de aproximadamente 220 hectares, composto pelos bairros da Praia Grande, Desterro, Apicum, Codozinho, Lira, Belira, Macaúba, Coreia e Madre Deus, conforme pode ser observado na Figura 1: 


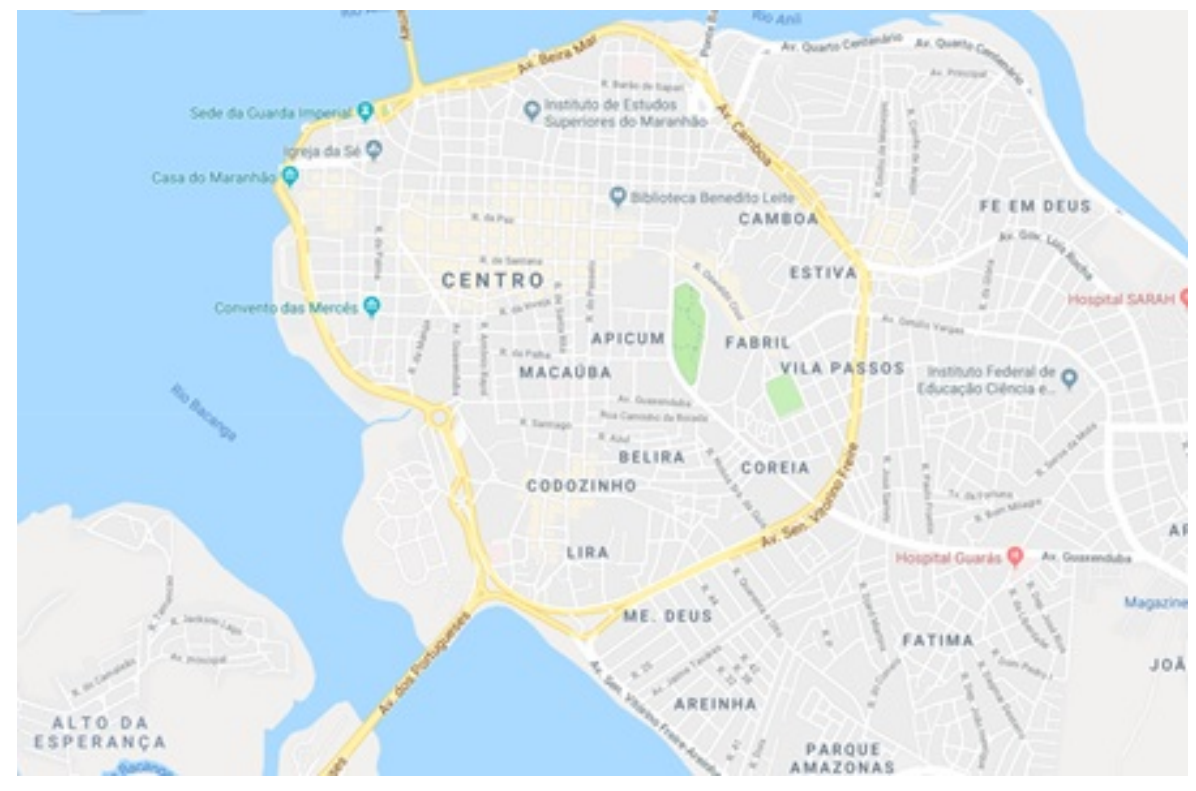

FIGURA 1

Mapa do centro de São Luís, Maranhão

Transportado pelos autores do Google Maps (2018)

Fundado pelos franceses por volta de 1612, o Centro Histórico teve então seu núcleo estabelecido. Após a batalha de Guaxenduba, os portugueses, então liderados por Jerônimo de Albuquerque, trouxeram a São Luís em 1615 o engenheiro Francisco Frias de Mesquita, incumbido de planejar todo aquele espaço (Mendes, Sousa, \& Marques, 2016).

Destaca-se que Mesquita,

[...] preparou um plano urbanístico, sendo utilizado como guia para a sua expansão e desenvolvimento dos colonizadores portugueses, tendo como característica principal o revestimento das fachadas dos casarões com azulejos, tendo como justificativa funcionar como um isolante térmico e serem resistentes, uma vez que as condições climáticas da ilha remetemse a períodos intensos de chuvas e de calor, logo, o ambiente interno das construções ficaria mais fresco e agradável (Mendes, Sousa, \& Marques, 2016, p. 4).

O plano urbano de São Luís apresentava os mesmos modelos arquitetônicos de outras cidades históricas, como Rio de Janeiro e Recife (Costa, 2017; Mendes, Sousa, \& Marques, 2016). Em meados de 1641, São Luís foi então tomada pelos holandeses, liderados por Maurício de Nassau. Destaca-se que nesse período algumas igrejas foram danificadas, a exemplo da Igreja do Desterro, a Igreja de São João Batista, esta última só foi recuperada cerca de vinte anos após a expulsão dos holandeses, em 1644, em um movimento liderado por Teixeira de Melo (Branco et al., 2017; Mendes, Sousa, \& Marques, 2016).

Desse modo, afirma-se que o Centro Histórico de São Luís “[...] retrata os conjuntos homogêneos remanescentes dos séculos XVIII e XIX representados pelos sobrados de fachadas revestidas em azulejos portugueses [...]" (Mendes, Sousa, \& Marques, 2016, p. 4). O Centro Histórico de São Luís apresenta um conjunto arquitetônico único, que expressa todo o poderio econômico da capital no período colonial, sobretudo pela abundância de azulejos portugueses. São Luís foi considerada como uma das cidades mais prósperas do País, graças à grande produção de algodão, arroz, dentre outros gêneros (Silva, 2009a).

Embora expressasse o apogeu da capital maranhense no período colonial, o Centro Histórico, a partir do século XX, foi sendo abandonado. Isso se deu pela saída dos moradores mais antigos, que foram ocupando outros espaços mais nobres da cidade, e pela queda do comércio no local, incidindo em "[...] processos de arruinamento de diversas construções do tecido urbano da referida área [...]” (Silva, 2009a, p. 2). 
Ressalta-se que na década de 1940 já se buscava colocar em vigência as prerrogativas do Decreto-Lei No25/1937, cujo objetivo era proteger os bens patrimoniais de grande valor para o País. Com isso ganha um novo fôlego a luta por proteger o conjunto arquitetônico do centro de São Luís. Segundo Andrès (1998, p. 104), o Maranhão dá um importante passo, a partir do "Tombamento Federal do Sambaqui do Pindahy, Processo 211-T-39; Inscrição no 6, Livro Arqueológico, Etnográfico e Paisagístico, Als. 02, 19/01/1940 [...]”, o primeiro tombamento federal no Estado (Silva, 2009a).

Pontua-se que outros tombamentos foram realizados, estes fundamentais para que o Centro Histórico de São Luís adquirisse ainda mais valor, sobretudo por seu arranjo arquitetônico. As ações destinadas à preservação dos bens patrimoniais do Maranhão, em especial os localizados em São Luís, foram consolidados em 1974 pelo Serviço de Patrimônio Histórico e Artístico Nacional (SPHAN) (Cutrim, Costa, \& Oliveira, 2017).

Segundo Silva (2009b, p. 1),

O tombamento arquitetônico e paisagístico do conjunto urbano do Centro Histórico de São Luís em 1974 pelo IPHAN (Processo no 454-T-57; inscrição no 64 do Livro do Tombo Arqueológico, Etnográfico e Paisagístico), veio a consolidar a política de tombamentos desenvolvidos pelo órgão desde a década de 1940 na cidade.

Consolidando-se como um momento de grande importância não apenas para o Maranhão, mas para o Brasil, nascia o Centro Histórico de São Luís, graças as ações do Instituto do Patrimônio Histórico e Artístico Nacional (IPHAN). Segundo Cutrim, Costa e Oliveira (2017), o Centro Histórico concentrava as principais atividades de preservação, uma vez que reunia um conjunto arquitetônico grandioso e "[...] por tratar-se de uma cidade histórica viva, pela sua própria natureza de capital que apesar de sua expansão, São Luís continuou preservando a malha urbana do século XVII e seu conjunto arquitetônico original" (Mendes, Sousa, \& Marques, 2016, p. 4-5).

Após o reconhecimento nacional do conjunto arquitetônico do centro de São Luís, em 6 de dezembro de 1997, o Centro Histórico foi reconhecido internacionalmente pela Organização das Nações Unidas para a Educação, a Ciência e a Cultura (UNESCO), recebendo, além do tombamento, o título de Patrimônio Cultural da Humanidade (Silva, 2017; Mendes, Sousa, \& Marques, 2016).

O Centro Histórico de São Luís, nos últimos anos, tem sido espaço de atividades diversificadas, dentre elas a Feira de Livros, festivais de música alternativa e popular brasileira, intervenções e ocupações artísticas. Tais práticas não apenas ressignificam, como dão uma nova perspectiva para esse espaço, carregado de memória e símbolos da cultura Maranhense. Na seção seguinte, discute-se como tais práticas, sobretudo as ocupações artísticas, incidem em ações de cidadania, preservação e valorização do patrimônio público do Estado.

\subsection{As ocupações artísticas e suas implicações para o patrimônio cultural de São Luís}

Embora os movimentos de ocupação artística no Centro Histórico de São Luís sejam de longa data - vide 30 anos do Coletivo A Vida é uma Festa conforme destaca Santos (2021) -, foi mediante a extinção do Ministério da Cultura, em maio de 2016, pelo governo interino de Michel Temer, que o termo ocupação toma maior significação de luta e resistência por parte da classe artística local, pelo movimento denominado OcupaMincMA, sendo São Luís uma das capitais pioneiras na ocupação de prédios do IPHAN por todo o Brasil, sob a alegação de ilegitimidade do governo vigente e perdas de direitos sociais básicos.

Desde então, no meio artístico dos coletivos atuantes no centro histórico da capital maranhense, embora já tivessem características de ocupações, tornou-se parte do discurso e do slogan das ações, de maneira mais incisiva, o formato de ocupação de espaços públicos como mecanismo da sociedade civil de manutenção e garantia do fazer cultural público, gratuito e para a comunidade.

Duran (2008) enxerga esses coletivos como legítimos representantes das mais diversas categorias da sociedade, os quais ocupam os espaços públicos não só com a intenção de utilizá-los para entretenimento e 
lazer unicamente, mas identificam os problemas ali presentes e encontram formas coletivas de solucioná-los, em oposição à cultura de espetáculo dos governos que criam públicos amestrados e apáticos, consumidores de uma narrativa pronta que não problematiza o espaço em que ela se insere.

É claro que há um esforço constante de marginalização destas iniciativas de base. As comunidades de afeto que aglutinavam artistas e promoviam contatos acabaram caminhando para a formação de guetos e redutos. O caráter marginal, comumente atribuído a estes grupos denota, por um lado, a forma como são apartados da vida "oficial" da cidade; mas aponta, por outro, que existem carências materiais e psicológicas a serem sanadas para que surja o sentimento de pertencimento necessário ao movimento próprio da cidade (Duran, 2008, p. 96-97).

Especificamente em São Luís, houve duas ações que se aproximam do fomento ao fazer artístico no formato de ocupações: o edital de Pontos de Cultura, realizado pela Prefeitura através da Secretaria Municipal de Cultura, em 2016, e 04 editais de ocupação em pontos específicos do centro histórico da cidade, em 2017. É importante ressaltar que ambas as ações eram voltadas majoritariamente para grupos e coletivos de cultura popular (Maranhão, 2017; Brasil, 2015). Tendo em vista a não continuidade das políticas públicas nas trocas de gestão, que não ocorre somente no Maranhão, mas em todo país, sempre há um déficit de ações afirmativas vigentes no campo da cultura, principalmente aquelas voltadas para o formato de ocupações artísticas.

É nesse cenário de incipientes ações de fomento e instabilidades na manutenção de políticas culturais que algumas ocupações resistem atuando no Centro Histórico de São Luís. Para melhor elucidar a discussão, tomam-se como exemplos duas ocupações com diferentes características de espaços, segmentos artísticos, formas de ocupação e tempo de trajetória, a fim de relacioná-las com os aspectos de preservação e valorização patrimonial.

A primeira delas é A Vida é uma Festa[2] (Figura 2) que, em suma, trata-se de um encontro de antigos músicos frequentadores do centro histórico de São Luís em um palco aberto de improvisos e shows musicais. As suas ações são tradicionais todas as quintas-feiras, nas noites da Praia Grande, há 30 anos. A programação ocupa a Rua Ladeira do Comércio, aos fundos do Centro de Criatividade Odylo Costa Filho com um tablado de madeira, caixas de som, microfones e alguns instrumentos musicais, construindo um claro convite à participação de qualquer um no palco aberto.

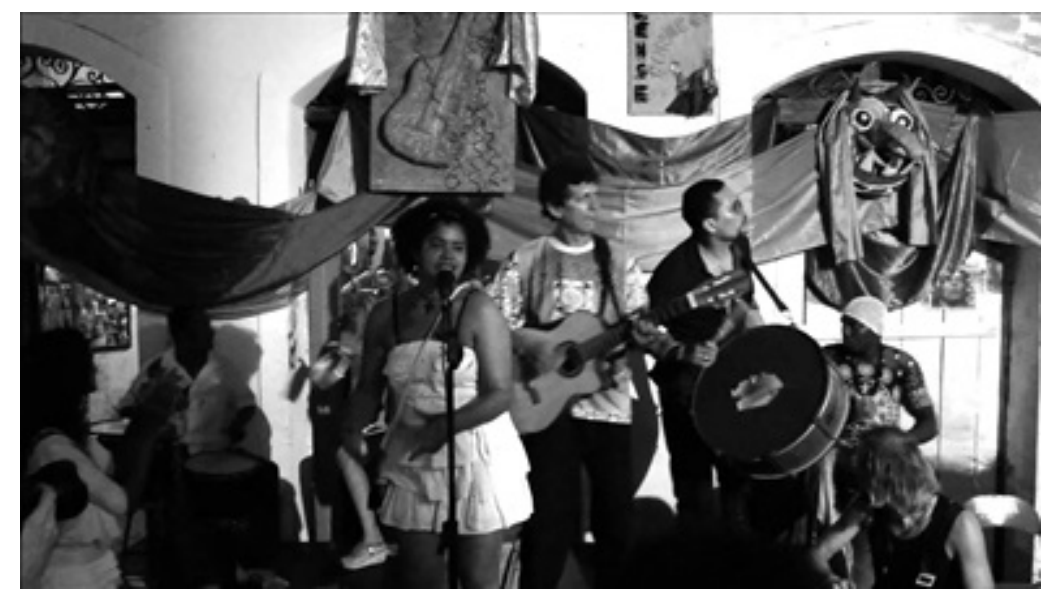

FIGURA 2

Show musical na ocupação A Vida é uma Festa

Youtube (2019)

Coordenado por Zé Maria Medeiros, cantor e compositor maranhense, o encontro é regado com diversas canções e sonoridades da cultura popular local, agregado às tradicionais rodas de Tambor de Crioula e shows musicais, ora improvisados, ora com grupos locais convidados. Observa-se que o carro-chefe das ações do coletivo são a manutenção das tradições da cultura popular maranhense, com instrumentos típicos dos ritmos 
tradicionais do Maranhão, como zabumbas e pandeirões do Bumba-meu-boi e o tambor grande ou rufador, meião ou socador e crivador ou perenga, que formam a parelha do Tambor de Crioula, dentre outros.

Além disso, A Vida é uma Festa ocupa o Casarão no 210 da Rua do Comércio há 28 anos, além da área da rua em frente ao imóvel. O movimento originário se chamava Companhia Circense que, antes da ocupação, promovia espetáculos com música e circo nas ruas do Centro Histórico de São Luís. Nos 10 primeiros anos, a Companhia permaneceu promovendo atividades internas e externas ao casarão ocupado, sendo nas noites de quinta-feira com roda de tambor de crioula e shows musicais, denominada A Vida é uma Festa. Com a dispersão da formação inicial, permaneceu esta última como principal ação da ocupação.

Por sua vez, o Coletivo O Circo Tá na Rua (Figura 3), como o nome sinaliza, ocupa a Praça Nauro Machado, localizada na Rua da Estrela ao lado do Teatro João do Vale, com treinos de circo públicos e gratuitos. Diferente da primeira, esta ocupação existe há sete anos e traz para o espaço público uma proposta de ação formativa, haja vista que muitos dos colaboradores diretos do coletivo iniciaram sua carreira de artista circense com a prática desenvolvida nos encontros. O grupo disponibiliza diversos materiais do universo do circo para a população experimentar e aprender, tais como pernas de pau, malabares diversos, área de tatames para acrobacias de solo e a alusão às tradicionais cordas bambas e arame através do slackline, prática de equilíbrio na fita em andar numa fita tensionada.
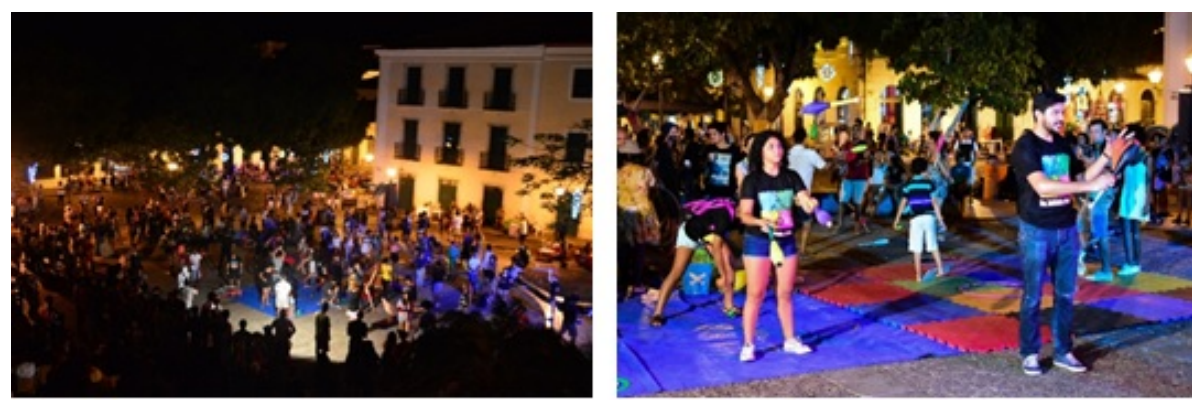

FIGURA 3

Coletivo O Circo Tá na Rua: Fotomontagem de registros

da oficina de circo realizada nas noites de segunda-feira

Elaborado a partir da Página do Facebook do Coletivo O Circo Tá na Rua (2017)

Neste a gestão é colaborativa. A coordenação das ações não está centrada em uma única pessoa. A estrutura organizacional do coletivo dá-se mediante colabores diretos, que participam das ações para além dos treinos semanais, e colaboradores indiretos, que são todos aqueles que frequentam os treinos assiduamente e colaboram assim para a manutenção do coletivo. Vale ressaltar a atuação em rede do grupo com outros coletivos socioculturais de bairros diversos da ilha como estratégia de fortalecimento das ocupações de espaços públicos.

Além das atividades principais, o Quadro 1 traz as ações secundárias realizadas pelas ocupações, desde ofertas de oficinas, realização de saraus, projeção de filmes, aulas de alongamento, reforço escolar e ações sociais, demonstrando um extenso rol de ações em benefício da comunidade do Centro Histórico do São Luís. Ligadas as estratégias necessárias para cobrir os custos inerentes à manutenção das ocupações, contam ainda com doações e recursos próprios dos ocupantes, além da reserva de um percentual da renda, gerada pelos serviços artísticos produzidos nos espaços para investimentos de limpeza, infraestrutura e materiais em geral. 


\begin{tabular}{|c|c|c|}
\hline \multicolumn{3}{|c|}{$\begin{array}{c}\text { QUADRO } 1 \\
\text { Caracterização das ocupações artístico-culturais }\end{array}$} \\
\hline & O Circo Tá na Rua & A Vida é uma Festa \\
\hline Atividades desenvolvidas & $\begin{array}{l}\text { - Oficina de Circo } \\
\text { - Saraus } \\
\text { - Apresentações de espetáculos } \\
\text { Shows musicais }\end{array}$ & $\begin{array}{l}\text { - Oficinas de Capoeira e Tambor } \\
\text { de Crioula } \\
\text { - Roda de Tambor de Crioula } \\
\text { - Shows musicais } \\
\text { - Palco aberto para apresentações } \\
\text { diversas }\end{array}$ \\
\hline Estratégias de manutenção & $\begin{array}{l}\text { - Eventos que mobilizam a } \\
\text { participação social e de outros } \\
\text { coletivos } \\
\text { - Porcentagem de cachê de } \\
\text { prestação de serviços } \\
\text { - Recursos próprios }\end{array}$ & $\begin{array}{l}\text { - Porcentagem de cachê de } \\
\text { prestação de serviços } \\
\text { - Recursos próprios }\end{array}$ \\
\hline Modificações estruturais & Nenhuma & $\begin{array}{l}\text { - Pintura das paredes } \\
\text { - Intervenções artísticas nas } \\
\text { paredes internas e externas }\end{array}$ \\
\hline Quantitativo de Ocupantes & $\begin{array}{l}30 \text { ocupantes do coletivo somado } \\
\text { ao fluxo de pessoas que frequentam } \\
\text { os encontros }\end{array}$ & $\begin{array}{l}\text { Aproximadamente } 10 \text { pessoas } \\
\text { somado ao fluxo de pessoas que } \\
\text { frequentam os encontros }\end{array}$ \\
\hline Organização Jurídica & $\begin{array}{l}\text { Microempreendedor } \quad \text { Individual } \\
\text { (MEI) }\end{array}$ & Não possui \\
\hline
\end{tabular}

Elaborado pelo Autor (2019)

Dentre as informações apresentadas no Quadro 1, cabe destaque às modificações estruturais realizadas pela ocupação A Vida é uma Festa, como mostra a Figura 4:
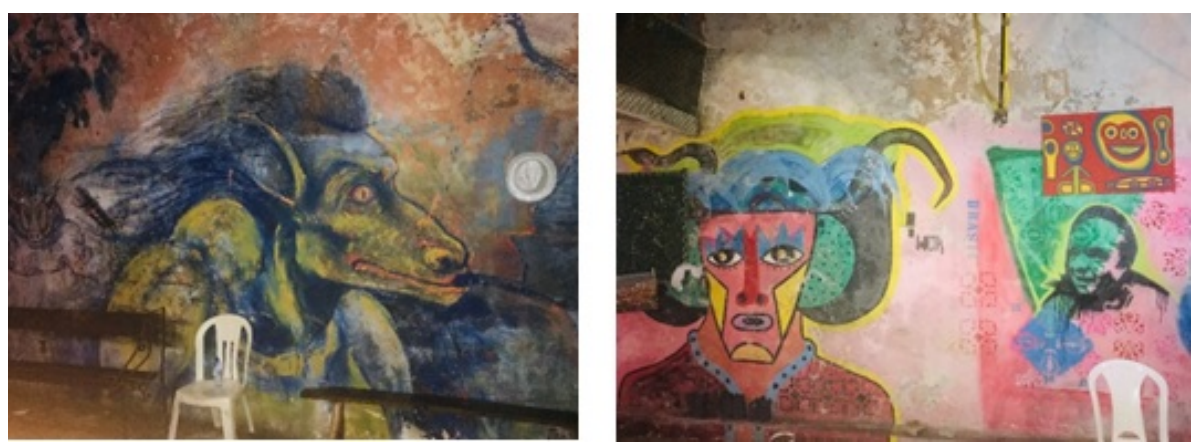

FIGURA 4

A Vida é uma Festa: Intervenções artísticas nas paredes internas do casarão ocupado Dados da pesquisa (2019)

Acerca das intervenções realizadas, o Artigo 17 do Decreto 25/1937, que organiza a proteção do patrimônio histórico e artístico nacional, estabelece que os bens federais tombados não podem ser pintados, restaurados ou reparados sem prévia autorização do órgão competente, sob pena de multa de $50 \%$ do valor do dano causado (Iphan, 1937). Brandão (2016) comenta acerca da contradição entre o aspecto positivo das ocupações artístico-culturais em fazer uso dos espaços de modo aberto à população e a ilegalidade das intervenções que atuam sem a autorização do corpo técnico dos órgãos de preservação. 
Em contraponto ao observado no instrumento de 1937, tais intervenções são consideradas por Brandão (2016, p. 69) como "[...] respostas sensíveis ao objeto histórico. São os casos de intervenções associadas com a identidade do grupo ou que se colocam como soluções criativas para as necessidades de uso". Tratam-se de obras de arte que consideram a autenticidade do imóvel, não modificam sua estrutura concreta original, porém demonstram a relação dos ocupantes com a materialidade do lugar ocupado, adicionando uma nova camada de história à já existente, atribuída ao edifício.

Da relação das ocupações com o patrimônio cultural, o principal fenômeno elucidado pelos ocupantes como motivação para ressignificar os espaços, dá-se pelos chamados "vazios urbanos", espaços abandonados pelos proprietários e pela administração pública que geram problemas de segurança pública para comunidade. A propósito da teoria do Urbanismo, esses vazios são espaços que perderam sua função social ou não se adequam às necessidades da população, gerando um efeito contrário, geralmente negativo, de evasão das pessoas que habitam e visitam o local, além de foco para atividades ilícitas e de violência urbana (Borde, 2006).

Ampliando o conceito, vazios urbanos não se limitam a imóveis abandonados, mas a todo e qualquer espaço público subutilizado na cidade, que carrega consigo uma potência criativa, a qual é enxergada pelos movimentos de ocupação, como no relato da ocupação O Circo Tá na Rua:

[...] a gente tinha o Circo da Cidade, onde pessoas mais antigas treinavam lá, mas acredito que a maioria da geração nossa, hoje em dia, não chegou a ter essa experiência de vivenciar lá. Talvez já tenha ido visitar, como eu fui visitar, como eu fui assistir coisas lá, apresentações artísticas, espetáculos, mas não chegou a treinar [...] por isso a gente começou a fazer coisas onde não se tinha onde fazer mais, não se tinha onde treinar circo em São Luís, a gente nem imaginava que se podia ter, até o dia que: 'vamos treinar na praça, vamos ocupar essa praça!', e virou essa ocupação com arte circense na cidade”, na segundafeira que também não acontecia nada lá, não tinha nada, era até escuro, eu lembro de fotos era um local até sombrio... (O Circo Tá na Rua, 2019, informação verbal).

Nesse caso, a ressignificação do espaço da praça ocorre como uma transposição ocasionada pela ausência do Circo da Cidade. O vazio urbano que a retirada do equipamento deixou, tanto na malha urbana quanto no imaginário da classe artística, em especial do segmento circo, mobiliza a necessidade de existência de um espaço público, que supra as necessidades de produção cultural nessa área e atenda uma demanda artística desamparada de equipamento cultural público específico para suas atividades.

Em ambas as ocupações, observa-se que a principal colaboração com a preservação e valorização do Centro Histórico de São Luís, enquanto patrimônio cultural, é a presença do povo no espaço patrimonial. Como posto por Gonçalves (1996, p. 97, grifo do autor), ao analisar o discurso do diretor do SPHAN, Rodrigo Melo de Franco Andrade, que ocupou o cargo em 1937 e permaneceu até o fim da década de 1960, “[...] o fator principal no processo de desaparecimento do patrimônio histórico e artístico nacional é a indiferença da população [...]", que supera as distinções de classes sociais e está ligada à perda da identidade cultural brasileira.

Nota-se que não somente nos equipamentos culturais, mas também nas ruas do Centro Histórico tem espaço para o fazer artístico, como coloca a ocupação A Vida é uma Festa (2019, informação verbal): “[...] A gente sempre trabalhava com a ideia de fazer arte na rua [...] eu acho isso uma coisa muito importante, a rua é um espaço aberto, democrático. As pessoas podem escolher estar ali [...]".

A dinâmica de uso da cidade dada pelos artistas vai de encontro àquela apontada por Oliveira Neto (2012), onde, desde o início do século XX, adota-se a privatização dos espaços de convivência como sinônimo de segurança e bem-estar social, colocando os espaços de convivência em zonas herméticas, como shoppings e condomínios fechados, enquanto a rua se torna um lugar de perigo e vulnerabilidade social.

Nesse sentido, as ações realizadas pelas ocupações artístico-culturais são por vezes marginalizadas. $\mathrm{O}$ Coletivo O Circo Tá na Rua faz um relato de tais situações:

A polícia, hoje em dia, a gente tenta só ignorar né, ignorar a existência. A Blitz Urbana já quis parar a gente, a polícia já tentou embaçar [atrapalhar, impedir]. A gente também não tenta peitar, eles ficam lá na deles e a gente fica na nossa [...] com essa galera [a polícia] a gente percebe que há uma barreira: eles tão pouco se importando com a gente e a gente tá ignorando também. A Blitz Urbana já tentou por duas vezes tirar a gente da praça porque a gente não tem uma autorização pra estar 
ali, sendo que a gente não faz nada além de colocar os materiais, a gente não fura a praça a gente não faz nada, tudo que a gente coloca a gente tira, e a gente até limpa o espaço que a gente suja quando faz alguma coisa a mais. (O Circo Tá na Rua, 2019, informação verbal).

É comum encontrar relatos de enfrentamento com a Polícia Militar em outras experiências de ocupação artístico-cultural, principalmente quando se trata de ações consideradas transgressoras, como o uso do grafitti na pesquisa de Monasterios (2011), Nasser (2018) e Chagas (2015). Quando há subversão à institucionalização da arte e a proposta de alteração da paisagem urbana zelada pela administração pública, os movimentos de ocupação acabam em enfrentamento direto com a polícia, além de ações de reintegração de posse e outras tentativas de impedir a realização das atividades.

Essa relação saudável entre a ocupação e o poder público aparece também no histórico da ocupação A Vida é uma Festa:

O Secretário de Cultura, que nos pôs aqui, tava na época no PRODETUR, que era o órgão encarregado do projeto de revitalização da Praia Grande, do Centro Histórico. No início, quando eles recuperaram isso aqui, que era uma área de abandono, muitos prédios foram entregues, não era nem comodato, eram entregues mesmo a pessoas... Quando já no final de mandato, ele [o Secretário] nos deu uma autorização para ocupar esse prédio, era o prédio inteiro, depois mudou o Governo, a gente teve ter que dividir o prédio: em cima ficou o COTEATRO, embaixo a gente, e aí estamos até hoje [...]. (A Vida é uma Festa, 2019, informação verbal).

Podem-se extrair algumas possíveis inferências a partir do relato acima. A primeira, diz respeito a possível relação de maior proximidade do poder público com as atividades artístico-culturais ou, a segunda, tal proximidade se deu por laços pessoais de proximidade/amizade com os membros da ocupação. Rubim (2007) aponta tais interferências, das relações pessoais dos que ocupam cargos políticos no direcionamento das políticas públicas de cultura no Brasil, com fins de contemplar interesses próprios, impedindo a totalidade do acesso a elas pela classe artística e população em geral.

Ressalta-se que esta análise não condena a cessão de espaços públicos para uso artístico-cultural seja realizada de forma facilitada, tampouco a proximidade do ente público com os agentes culturais locais dos mais variados formatos e segmentos artísticos, mas que faça parte da agenda pública federal, estadual e municipal o reconhecimento e inserção das ocupações artístico-culturais como ações legítimas que contemplam as dimensões do conceito de cultura proposto no PNC 2010-2020 (Brasil, 2008, p. 11) que

[...] se propõe a "cultivar" as infinitas possibilidades de criação simbólica expressas em modos de vida, motivações, crenças religiosas, valores, práticas, rituais e identidades. Para desfazer relações assimétricas e tecer uma complexa rede que estimule a diversidade, o PNC prevê a presença do poder público nos diferentes ambientes e dimensóes em que a cultura brasileira se manifesta. As políticas culturais devem reconhecer e valorizar esse capital simbólico, por meio do fomento à sua expressão múltipla, gerando qualidade de vida, auto-estima [autoestima] e laços de identidade entre os brasileiros.

A partir desse reconhecimento das ações das ocupações em sua dimensão simbólica - pela valorização dos modos de viver, dimensão cidadã - pela promoção de acesso universal aos bens culturais e equipamentos públicos da cidade e, na dimensão econômica - pelas suas atividades prezarem pelo uso sustentável e comunitário dos espaços, evitando seu uso predatório e destrutivo nos monopólios comerciais, bem como a tentativa de fomentar um desenvolvimento econômico justo e sustentável, amparando "[...] fluxos de formação, produção e difusão adequados às singularidades constitutivas das distintas linguagens artísticas e múltiplas expressões culturais [...]" (Brasil, 2008, p. 12).

Nota-se que as ocupações artísticas reivindicam a preservação e valorização patrimonial através do seu uso, mediante a aproximação das pessoas com os bens culturais que compõem a história do local e da nação. $\mathrm{O}$ distanciamento produzido, tanto pelas leis quanto pela indústria da mercantilização do capital cultural, esvaise no instante em que a população toma para si os espaços e a partir deles desenvolve ações voltadas para o bem-estar social, na perspectiva de revitalizar espaços públicos subutilizados e, de fato, contribuir para a democratização da cultura. 
Longe de simplificar a salvaguarda do patrimônio do Centro Histórico de São Luís à utilização dos espaços públicos pela população, destaca-se que a relação que as pessoas desenvolvem com o espaço no fortalecimento do reconhecimento identitários delas com os bens culturais presentes nas áreas patrimoniais, corroborase a ideia de patrimônio socializado, no qual os sujeitos habitam, utilizam e se tornam parte do lugar, reconhecendo a memória e história daquele espaço como parte da sua própria identidade (Almeida, 2017; Choay, 2009).

A relação entre as ocupações e o patrimônio se aproxima da perspectiva dinâmica que preconiza seu contínuo desenvolvimento, com modificações advindas dos usos contemporâneos que lhe são dados, colocando os sujeitos como parte dele, como aponta o relato abaixo:

[...] Essas ocupações artísticas, eles sabem que pontos são aqueles, eles não vão ali à toa, eles tem um cuidado, eles sabem do que é, ou talvez foi aquele casarão, e aí falam assim: “- vamo preservar esse local até porque se pode ter mais [...] retorno desse local, quanto mais eu cuido desse local, eu posso permanecer mais tempo nele, eu posso fazer com que mais pessoas possam ter essa experiência nesse local, e eu continuo preservando minha São Luís, né?" Com toda história que ela carrega, e eu acabo colocando mais uma história nesse espaço... como uma ocupação artística, que preserva esse local, que quer dar mais movimento. (O Circo Tá na Rua, 2019, informação verbal).

Essa prática, da função social do espaço público patrimonial para as pessoas, apresenta-se como uma resistência ao processo de patrimonialismo por vezes inerente aos programas de revitalização de centros históricos no Brasil. Trata-se da conduta, por parte da esfera pública, que gera a indistinção entre o público e o privado, em virtude da instrumentalização do poder do Estado para interesses próprios, em geral comungados com os de grandes empresas com capital financeiro para investir na reestruturação urbana desses locais, que correspondam aos seus interesses lucrativos (Almeida, 2017).

Mediante o contexto, após a caracterização e análise das ocupações aqui estudadas, os atos coletivos de ocupação se colocam, além da postura política de resistência, como ações práticas demonstrativas das ressignificações desses espaços, buscando contemplar questões culturais, sociais, econômicas, bem como agentes de promoção da cidadania, por meio da participação social ativa, direta, consciente da preservação do patrimônio e disposta a transformá-lo em benefício da cidade. Pode-se afirmar que tanto as ocupações de habitação quanto as artístico-culturais, são preteridas nos programas de reestruturação urbana em andamento desde o ano de 2019, quando comparadas a investimentos com fins mercadológicos, ratificando o direcionamento empresarial que está sendo dado ao Centro Histórico de São Luís.

Assim, como propõe Lefebvre (2008), a arte poderia se ocupar justamente desse porvir, em criações não apenas artísticas, mas urbanas, em escala social, transformando práticas diárias em formas de viver a cidade como obra de arte, de pertencimento à coisa urbana. Alinhando-se, como fazem as ocupações artísticoculturais, à ideia de cultura presente no PNC 2010-2020 (Brasil, 2008), enquanto um conceito transversal, que perpassa por todas as instâncias da vida humana, não de forma contemplativa, mas enquanto elemento estruturante do ser social, que se relaciona com os outros, com o espaço à sua volta, compreendendo a cidade como um projeto em construção, exorável pela ação coletiva colaborativa entre o poder público e a sociedade civil.

As ocupações artístico-culturais constroem espaços urbanos ressignificados à medida que, além de lhes dar novos usos, instigam a população a repensar a cidade, estreitando sua relação com o espaço público por meio de estratégias de apropriação com o uso da arte, nas suas dimensões de entretenimento e lazer, bem como de formação e profissionalização. No caso do Centro Histórico de São Luís, foram identificadas práticas relacionadas aos segmentos artísticos da Música, Teatro, Circo e Cultura Popular, em formato de apresentações e oficinas.

Articula-se, no espaço público, uma espécie de resistência política por parte de quem os ocupa, tanto para preservá-lo como área de fomento e fruição da produção cultural local, garantindo que existam espaços que contemplem sua diversidade artística, quanto para pressionar a esfera pública a direcionar os investimentos 
em equipamentos culturais, que atendam às necessidades da população, em especial para aqueles que ainda habitam o Centro Histórico de São Luís, e não somente com fins turísticos e de espetacularização.

Em síntese, as ocupações artístico-culturais mostram um potencial enquanto movimento social de mobilização coletiva de atuação em espaços públicos, pautadas sobretudo na reivindicação do direito à cidade, instrumentalizando o fazer artístico como ferramenta de transformação dos modos de vida urbana, minimizando os efeitos de mercantilização generalizada que alcança o cotidiano das pessoas, bem como para promover a difusão e democratização dos bens culturais e do exercício da cidadania, pelo livre acesso dos espaços públicos, sem distinção de gênero, raça ou classe social.

\section{Considerações Finais}

Desde as primeiras tentativas em estabelecer uma concepção para patrimônio, viu-se que este esteve relacionado a diferentes conceitos, representando aspectos que perpassam desde as noções de filiação, monumentos, bem como os traços identitários, dentre outros elementos. Entende-se que, mesmo com diferentes terminologias - patrimônio material, imaterial, cultural etc. - estas convergem nas distintas dimensões que o patrimônio contempla.

Todos os elementos que constituem a percepção de patrimônio nada mais são que bens patrimoniais que independente, de sua tipologia ou classificação, devem ser preservados e mantidos vivos, pois retratam a memória, a identidade, a história, os saberes e fazeres de um povo, logo, devem chegar às gerações seguintes. Desse modo, percebe-se que as concepções de patrimônio serão ressignificadas com o passar dos anos, refletindo as diferentes realidades demarcadas no tempo e no espaço.

As pesquisas encontradas acerca da preservação e revitalização do Centro Histórico de São Luís perpassa em sua maioria pela questão arquitetônica do Patrimônio Material e outros referentes ao Patrimônio Imaterial de segmentos tradicionais da cultura popular como Tambor de Crioula e Capoeira. Na contramão dessa solidificação, da ideia de patrimônio como contemplação do passado e das tradições, as ocupações se ancoram nas correntes que o entendem como um conjunto de bens coletivos, pertencentes à memória coletiva dos que ali habitam e constroem sua identidade no cotidiano das relações estabelecidas com aquele espaço patrimonial, bem como na produção de novos bens culturais.

Em caráter estrito, observa-se as peculiaridades que cada ação artístico-cultural agrega ao espaço público. Ações micropolíticas de resistência, ocupação e apropriação por parte da classe artística geram demandas que reverberam na comunidade que habita o Centro Histórico; em quem está só de passagem, como o turista, nacional, estrangeiro ou local, bem como no ente público, em específico nas instituições responsáveis pela administração, manutenção, planejamento e preservação do patrimônio histórico que o compõem.

Assim, as ocupações artísticas perpassam o tempo e o espaço, trazendo-lhe ressignificações e possibilitando a permanência dinâmica da ideia de que patrimônio cultural não se limita a ruínas, casarões monumentais ou de obras e documentos intocáveis. Afastando-se das concepções hegemônicas de identidade nacional e hipervalorização do tradicional, elas trazem para o espaço público novas possibilidades de pensar e problematizar as políticas de preservação patrimonial que, para além de preservar a história, precisa permitir que o povo se reconheça enquanto parte dela e possa participar ativamente da sua valorização e (re)construção.

Não seria possível esgotar com este estudo a complexidade que envolve os usos e funções sociais dos espaços públicos patrimoniais do Centro Histórico de São Luís. Sinalizam-se algumas possibilidades de novos estudos e pesquisas científicas que: a) acompanhem os programas de reestruturação e revitalização em andamento; b) mapeiem os vazios urbanos do seu conjunto arquitetônico e investiguem as possibilidades de usos, a fim de traçar estratégias que facilitem sua reativação; c) proponham a desburocratização para utilização dos espaços públicos referentes a atividades de cunho social, em benefício comunitário; d) reconheçam a relevância social presente nas ações das ocupações artístico-culturais, haja vista a oferta de atividades públicas e gratuitas; e) 
colaborem para a formulação de políticas públicas de cultura, bem como de equipamentos públicos, que contemplem as ações artísticas em formato de ocupação; f) outras iniciativas.

Ressignificar o espaço público patrimonial está diretamente ligado à garantia do direito à cidade, reconhecendo a sua dinâmica enquanto um projeto em construção coletiva, com participação das esferas pública, privada e sociedade civil. As ocupações artístico-culturais se colocam, em medida, como um termômetro senciente ao equilíbrio da relação dessas esferas, atuando em formato de protesto e resistência ao desequilíbrio de interesses que impactam o espaço da cidade, assim como um mecanismo de contínuo alerta para reflexão sobre o lugar que a população ocupa nesse contexto, ratificando a necessidade da participação social direta no campo social da disputa de poder entre tais agentes sociais.

\section{REFERÊNCIAS}

Almeida, M. F. (2017). Processos urbanos de patrimonialização mundial: espaços de contradição e ressignificação dos tecidos urbanos patrimoniais. [Tese de Doutorado em Arquitetura e Urbanismo] Universidade de São Paulo, São Carlos.

Andrès, L. P. de C. C., coordenador (1998). Centro Histórico de São Luis-MA: Patrimônio mundial. São Paulo: Audichomo.

Borde, A. L. C. (2006). Vazios Urbanos: perspectivas contemporâneas. [Tese de Doutorado em Urbanismo] Universidade Federal do Rio de Janeiro, Rio de Janeiro.

Branco, A. A. et al. (2017). Bumba meu Guia: um aplicativo mobile para guia turístico do Centro Histórico de São Luís - MA: as igrejas do período colonial de São Luís como atrações turísticas. Acta Brazilian Science, 5(1).

Brandão, M. C. (2016) Ocupar o Patrimônio: reflexões sobre estudos de casos. [Monografia de Graduação em Arquitetura e Urbanismo] Universidade de São Paulo, São Paulo.

Brasil (2008). Plano Nacional de Cultura: Diretrizes Gerais. Brasília, DF: Governo Federal.

Brasil (2015). O que é a Politica Nacional de Cultura Viva - PNCV? Brasilia, DF: Ministério da Cultura.

Chagas, J. A. (2015) Pixação e as linguagens visuais no bairro Benfica: uma análise dos modos de ocupação de pixos e graffiti e de suas relações entre si. [Dissertação de Mestrado em Sociologia] Universidade Federal do Ceará, Fortaleza.

Chaves, C. R. C. (2012). Educação patrimonial no bairro do Desterro: estudos sobre os projetos de patrimonialização no Centro Histórico de São Luís - MA. [Dissertação de Mestrado em Cultura e Sociedade] Universidade Federal do Maranhão, São Luís.

Choay, F. (2009). A alegoria do patrimônio. Tradução de Luciano Vieira Machado. 4. ed. São Paulo: Estação Liberdade: UNESP.

Conceição, M. V. C. (2011). Henri Lefebvre e a Internacional Situacionista: o debate sobre a Comuna de Paris no contexto do Maio de 1968. [Apresentação de Trabalho] Simpósio Nacional de História, São Paulo: ANPUH.

Costa, V. D. F. de C. (2017). A invenção do centro histórico de São Luís/MA: sentidos de um lugar de memória. [Monografia de Graduação em Ciências Sociais]. Universidade de Brasília, Brasília, Brasília, DF.

Cutrim, K. D. G., Costa, S. R., \& Oliveira, W. A. (2017). Valorização do Centro Histórico de São Luís - MA e novas maneiras de consumo da música: um olhar sobre o festival BR 135. RICS, 3.

Durán, M. (2008). La Ciudad Compartida: conocimiento, afecto y uso. Santiago de Chile: Ediciones Sur.

Fernandes, A. M. V. (2017). Patrimônio Cultural, Turismo e a renovação das cidades: aproximações e dissonâncias entre Barcelona e Rio de Janeiro. [Tese de Doutorado em Geografia] Universidade Estadual de Campinas, Campinas, SP.

Ferreira, M. M. G. (2008). O Centro Histórico de São Luís: fronteiras e regiões. Outros Tempos, 5(5).

Fonseca, M. C. L. (2009). Para além da pedra e cal: por uma concepção ampla de patrimônio cultural, In: R. Abreu, \& M. Chagas. Memória e patrimônio: ensaios contemporâneos (pp. 59-79). Rio de Janeiro: Lamparina.

Funari, P. P., \& Pelegrini, S. C. A. (2009). Patrimônio histórico e cultural: passo a Passo. Rio de Janeiro: Jorge Zahar. 
Garcia, C. G. (2017). Cultura e Cidade: novas configurações socioespaciais na era pós-industrial. [Apresentação de Trabalho] Encontro Nacional da Associação Nacional de Pós-Graduação e Pesquisa em Planejamento Urbano e Regional, São Paulo.

Gonçalves, J. R. S. (1996). A Retórica da Perda: os discursos do patrimônio cultural no Brasil. Rio de Janeiro: Editora UFRJ; IPHAN.

Grimaldi, S. S. L. (2016). Memória da Ciência e da Tecnologia: preservação do Patrimônio Cultural Brasileiro. [Dissertação de Mestrado em Ciência da Informação] Universidade Federal de Pernambuco, Recife.

IBGE. (2021). Cidades e estados: São Luís. Rio de Janeiro: [s.n.]. Recuperado de https://www.ibge.gov.br/cidades-eestados/ma/sao-luis.html.

Iphan (1937). Decreto Lei nº 25, de 30 de novembro de 1937. Organiza a Proteção do Patrimônio Histórico e Artístico Nacional. Brasília, 1937.

Lefebvre, H. (2008). O direito à cidade. São Paulo: Centauro.

Maranhão. (2017). Governo do Maranhão lança editais de ocupação artística. São Luís.

Marconi, M. A., \& Lakatos, E. M. (2017). Fundamentos de metodologia cientifica. São Paulo: Atlas.

Medeiros, A. E. de A. (2002). Materialidade e imaterialidade criadoras: o Global, o Nacional e o Local na construção do Patrimônio Cultural - O Bairro do Recife como caso. [Tese de Doutorado em Sociologia] Universidade de Brasília, Brasília, DF.

Mendes, J. N., Sousa, I. B. B., \& Marques, A. R. (2016). A importância da preservação do Centro Histórico de São Luís do Maranhão como Patrimônio Cultural da Humanidade. [Apresentação de Trabalho] Encontro Nacional de Geógrafos. São Luís: EDUFMA.

Monasterios, S. T. S. (2011). Arte ou ocupação? O graffiti na paisagem urbana de São Paulo. [Dissertação de Mestrado em Educação, Arte e História] Universidade Presbiteriana Mackenzie, São Paulo.

Moreaux, M. P. (2013). Expressóes e impressóes do corpo no espaço urbano: estudo das práticas de artes de rua como rupturas dos ritmos do cotidiano da cidade. [Dissertação de Mestrado em Geografia] Pontifícia Universidade Católica do Rio de Janeiro, Rio de Janeiro.

Nasser, E. (2018). Arte e (R)existência: grafites na cidade de São Paulo à luz da teoria crítica. [Dissertação de Mestrado em Psicologia Social] Universidade de São Paulo, São Paulo.

Noronha, R. (2015). No coração da Praia Grande. São Puís: EdUFMA.

Oliveira Neto, S. (2012). Situação Prestes Maia: o processo de colaboração entre artistas, coletivos artísticos e o Movimento Sem-Teto do Centro (MSTC). Ocupação Prestes Maia/São Paulo (2003-2007). [Dissertação de Mestrado em Estética e História da Arte] Universidade de São Paulo, São Paulo.

Paiva, R., \& Gabbay, M. (2016). Cidade, Afeto e Ocupações: ou a transfiguração do espaço público no Brasil contemporâneo. [Apresentação de Trabalho] Sociedade Brasileira de Estudos Interdisciplinares da Comunicação, São Paulo.

Pereira, V. C. (2017). O tombamento da caixa d'água da Ceilândia no contexto da Política de Patrimônio do Distrito Federal. [Dissertação de Mestrado em Ciência da Informação] Faculdade de Ciência da Informação, Universidade de Brasília, Brasília.

Rocha, R. P. (2018). Patrimônio cultural imaterial de Itaituba/Pará. [Dissertação de Mestrado em História] Pontifícia Universidade Católica de Goiás, Goiânia.

Rubim, A. A. C. (2007). Políticas culturais no Brasil: tristes tradições. Revista Galáxia, 7(13).

Sampieri, R. H., Collado, C. F., \& Lucio, M. P. B. (2013). Metodologia de pesquisa. Porto Alegre: Penso.

Santos, D. W. (2020). Usos da cidade: ocupações artístico-culturais de espaços públicos patrimoniais do Centro Histórico de São Luís. [Dissertação de Mestrado em Cultura e Sociedade] Universidade Federal do Maranhão, São Luís.

Santos, S. R., \& Lorêdo, C. D. (2013). A Casa das Tulhas e a Feira da Praia Grande: produto turístico em São Luís, MA. Revista Rosa dos Ventos, 5(3). 
Donny Wallesson dos Santos, et al. Ocupações artísticas no Centro Histórico de São Luís, Ma: revit...

Sartori, E., \& Garcia, C. H. M. (2013). Políticas Públicas e Espaço Público: aproximações teóricas-conceituais no contexto brasileiro. [Apresentação de Trabalho] Encontro Internacional - participação, democracia e políticas públicas: aproximando agendas e agentes. Araraquara, SP: UNESP.

Silva, J. R. C. (2009a). Políticas Públicas no Centro Histórico de São Luís: as etapas do processo de intervenções urbanísticas. [Apresentação de Trabalho] Jornada Internacional de Politicas Públicas. São Luís: EDUFMA.

Silva, J. R. C. (2009b). O processo de patrimonialização do centro antigo de são luís: práticas patrimoniais desenvolvidas pelo poder público. [Apresentação de Trabalho] Simpósio Nacional de História. Fortaleza: ANPUH.

Silva, R. H. T. (2017). Patrimônio cultural: construção do passado e do futuro em São Cristóvão (SE). Revista Geografa e Pesquisa, 11(1):13-20.

Studart, V. M. (2017). Integração sistêmica da atividade estatal de proteção do Patrimônio Cultural no Brasil. [Dissertação (Mestrado em Direito Constitucional] Universidade de Fortaleza, Fortaleza.

Vogt, O. P. (2008). Patrimônio cultural: um conceito em construção. MÉTIS. história \& cultura, 7(13): 13-31.

\section{Notas}

[1] Conforme o IBGE (2021), Ludovicense é o gentílico utilizado para São Luís, capital do Maranhão.

[2] Para saber mais, acesse os links: e. Acesso em: 20 nov. 2019. 